Article

\title{
Environmental Sustainability of Bioenergy Strategies in Western Kenya to Address Household Air Pollution
}

\author{
Ricardo Luís Carvalho ${ }^{1,2, *}$ (D) Pooja Yadav ${ }^{3}$, Natxo García-López ${ }^{1}$, Robert Lindgren ${ }^{1}$, \\ Gert Nyberg ${ }^{4}$, Rocio Diaz-Chavez ${ }^{5}$, Venkata Krishna Kumar Upadhyayula ${ }^{6}$, \\ Christoffer Boman ${ }^{1}$ and Dimitris Athanassiadis ${ }^{3}$ (D) \\ 1 Thermochemical Energy Conversion Laboratory, Department of Applied Physics and Electronics, \\ Umeå University, 90187 Umeå, Sweden; natxo.garcia@umu.se (N.G.-L.); robert.lindgren@umu.se (R.L.); \\ christoffer.boman@umu.se (C.B.) \\ 2 Centre for Environmental and Marine Studies, Department of Environment and Planning, \\ University of Aveiro, 3810-193 Aveiro, Portugal \\ 3 Department of Forest Biomaterials and Technology, Swedish University of Agricultural Sciences, \\ 90183 Umeå, Sweden; pooja.yadav@slu.se (P.Y.); dimitris.athanassiadis@slu.se (D.A.) \\ 4 Department of Forest Ecology and Management, Swedish University of Agricultural Sciences, 90183 Umeå, \\ Sweden; gert.nyberg@slu.se \\ 5 Stockholm Environment Institute, Africa Centre, World Agroforestry Centre, Nairobi 30677, Kenya; \\ rocio.diaz-chavez@sei.org \\ 6 Department of Chemistry, Umeå University, 90187 Umeå, Sweden; krishna.upadhyayula@umu.se \\ * Correspondence: ricardo.teles@ua.pt; Tel.: +46-907-866-756
}

Received: 31 December 2019; Accepted: 5 February 2020; Published: 7 February 2020

check for updates

\begin{abstract}
Over 640 million people in Africa are expected to rely on solid-fuels for cooking by 2040. In Western Kenya, cooking inefficiently persists as a major cause of burden of disease due to household air pollution. Efficient biomass cooking is a local-based renewable energy solution to address this issue. The Life-Cycle Assessment tool Simapro 8.5 is applied for analyzing the environmental impact of four biomass cooking strategies for the Kisumu County, with analysis based on a previous energy modelling study, and literature and background data from the Ecoinvent and Agrifootprint databases applied to the region. A Business-As-Usual scenario (BAU) considers the trends in energy use until 2035. Transition scenarios to Improved Cookstoves (ICS), Pellet-fired Gasifier Stoves (PGS) and Biogas Stoves (BGS) consider the transition to wood-logs, biomass pellets and biogas, respectively. An Integrated (INT) scenario evaluates a mix of the ICS, PGS and BGS. In the BGS, the available biomass waste is sufficient to be upcycled and fulfill cooking demands by 2035. This scenario has the lowest impact on all impact categories analyzed followed by the PGS and INT. Further work should address a detailed socio-economic analysis of the analyzed scenarios.
\end{abstract}

Keywords: agroforestry; waste valorization; sustainable development goals; renewable energy; bioenergy transitions; circular bioeconomy; clean cooking; life-cycle assessment; energy policy

\section{Introduction}

It is estimated that over $40 \%$ of the world's population is currently relying on solid-fuels for cooking and heating [1]. According to the World Health Organization (WHO), the inefficient utilization of biomass and coal for these purposes constitutes today's largest global environmental health risk [2,3]. Worldwide, over 4 million deaths occur per year from illnesses related to the smoke from solid-fuel combustion indoors, which mainly affects women and children [4,5]. In developing countries, wood and charcoal continue to play a vital role in meeting household energy demands, where it remains easily accessible and affordable [6-8]. Thus, the transition to cleaner cooking fuels in advanced cookstoves 
constitutes an important way to address several of the 17 Sustainable Development Goals (SDGs) [9,10], contributing to address at least five of the SDGs, including the: (1) Good health and well-being (SDG 3); (2) Gender equality (SDG 5); (3) Affordable and clean energy (SDG 7); (4) Climate action (SDG 13); and (5) Life on land (SDG 15).

In Sub-Saharan Africa (SSA), only $35 \%$ of the population have access to electricity and $80 \%$ of the people rely on traditional firewood, charcoal, animal dung and agricultural residues for cooking [11,12]. Negative environmental impacts such as global warming due to the emission of carbon dioxide $\left(\mathrm{CO}_{2}\right)$, nitrous oxide $\left(\mathrm{N}_{2} \mathrm{O}\right)$ and methane $\left(\mathrm{CH}_{4}\right)$, eutrophication related with the emission of nitrogen oxides $\left(\mathrm{NO}_{\mathrm{x}}\right)$ and $\mathrm{N}_{2} \mathrm{O}$, acidification associated with the emission of sulphur dioxide $\left(\mathrm{SO}_{2}\right)$ and $\mathrm{NO}_{\mathrm{x}}$, and toxicological effects on humans related with the emission of $\mathrm{NO}_{x}$ and particulate matter (PM) are potentially intensified by traditional cooking. In Kenya, the cooking sector emissions are driven by rapid population and economic growth [13], and household air pollution (HAP) causes 15,600 deaths with direct impacts on the health of around 15 million people [14-17].

In the Kenyan context, the transition to advanced cookstoves using upgraded biomass fuels (e.g., wood pellets and biogas) produced via renewable energy strategies constitutes a relevant way to mitigate HAP. Such locally produced biofuels based on waste valorization and agroforestry strategies have a great potential to enhance land restoration and livelihoods, as agroforestry is a powerful tool to enhance multiple ecosystem services [18]. Famers in Kenya are responsible for producing a substantial part of the food consumed in the region. In this context, an integrated management of crop-residues at the farm scale can tackle challenges of food security, poverty and climate change $[18,19]$. Furthermore, the utilization of crop-residues remains an opportunity for sustainable bioenergy production in rural and peri-urban communities [20]. In such a perspective, the Kenyan government has worked on designing proper strategies towards the deployment of efficient bioenergy systems [21,22], including the use of both agricultural crop [23] and industrial biomass residues [21] for the production of biogas and densified biomass fuels. The Kenya Country Action Plan (CAP) for Clean Cookstoves and Fuels has established a target to promote the installation of cleaner cookstoves in 5 million households by 2020 [24]. With a thermal efficiency over two times higher than that achieved by improved cookstoves using wood-logs and sticks $[25,26]$, advanced biomass cooking solutions such as micro-gasifier and biogas cookstoves can be key in technologies to address such clean cooking systems.

Despite the existing initiatives, there is currently a knowledge gap on how to design sustainable cooking strategies in the context of emerging circular bioeconomies. Few studies have analyzed the life-cycle environmental impact of integrated biomass fuel/cookstove strategies on the mitigation of HAP at the sub-national level. Various studies have been analyzed the impact of different energy transition options $[8,27,28]$. In Western Kenya, Carvalho et al. [26] have applied the Long-Range Energy Alternative Planning (LEAP) software to analyze the energy savings and emissions caused by distinct bioenergy strategies on HAP in Kisumu County. The study was applied for the time span between 2015 and 2035, showing part of the environmental benefits of such strategies. Although the previous energy modelling study [26] shows the HAP mitigation potential at the sub-national level, there is currently a limited number of studies assessing the overall environmental performance of these transitions in a life-cycle assessment (LCA) perspective.

As defined by the International Standard Organization (ISO) in the ISO 14040 [29], LCA is a technique used to quantify the environmental impacts of a product system like a cooking fuel over its whole life cycle, from raw material acquisition through production, use, end of life, treatment, recycling, and disposal [29]. A previous LCA study conducted in Kenya observed that biogas from animal dung and ethanol from wood as cooking fuels had the best environmental performance in almost all environmental impact categories while charcoal briquettes from wood exhibited poor environmental performance due to emissions resulting from kiln operation [30]. Okoko et al. [31] confirmed the higher carbon footprint of unimproved charcoal value-chain in relation to alternative biomass energy solutions for cooking in Kenya and Tanzania. Lansche and Müller performed a comparative LCA on traditional biomass and biogas household cooking systems in Ethiopia, demonstrating the high 
potential for environmental improvements when adopting biogas systems. Although the previous LCA studies analyzed the environmental impacts of alternative cooking value-chains in a certain static moment in time, they did not include a LCA considering regional energy forecasts, i.e., a dynamic LCA approach [32]. The dynamic LCA method can be applied to analyze environmental impacts in different time spans. Pehnt [33], for instance, considered the time-variation of electricity mix in the assessment of GHGs and acidification impacts. García-Gusano et al. [34] combined energy forecasts using LEAP with a dynamic LCA approach to evaluate the effects of various coal power plant retrofits over time. Although various dynamic LCA studies conducted, there is currently a lack of approaches dedicated to analyzing household energy transitions in the developing region context.

In the present research, a dynamic LCA based data provided by a previous energy forecast study [26] is conducted to determine the environmental sustainability of emerging biomass cooking strategies in the Kisumu County (Western Kenya). Although most biomass cookstoves have not progressed to the point that they are equivalent to Liquefied Petroleum Gas in terms of efficiency and cleanliness in the household indoor environments [35], this study is confined to evaluate the advances in the local use of biomass resources in the context of renewable energy and bioeconomy transitions. WIth this background, the present work constitutes not only an LCA of alternate biomass value-chains, but also a methodological development in the integration of LEAP/LCA tools for the analysis of the environmental sustainability of distinct energy policies. Despite the fact that several studies have conducted life-cycle analysis of products and systems at the country $[34,36]$ and city levels $[37,38]$, few have combined integrated energy models with LCA to evaluate the environmental impact of energy policy scenarios at the sub-national level. The Kisumu County in Western Kenya was selected for the case study as it presents a large availability of endogenous biomass resources, including agricultural and industrial residues that can potentially be used for the production of cooking biofuels. The region presents an important area of fertile agricultural land that may serve for the establishment of local-based agroforestry systems [39,40], which can be used to produce wood fuel in a more sustainable and resilient manner.

\section{Materials and Methods}

The present study is focused on analyzing the environmental performance of four bioenergy transition strategies for household cooking in the Kisumu County (Kenya), considering the importance of biomass local resources for addressing the resilience of communities in the developing country context. The study uses some of the results from a previous energy modelling study [26] as input data to conduct a dynamic LCA. Although the study does not measure the economic and social implications of the different transition scenarios, the design of the different scenarios for the environmental assessment is based on the premise that the efficient valorization and use of local biomass resources is an important waste management solution [31]. Additionally, this study includes the application of woody agroforestry biomass systems, which are powerful tools to enhance access to energy and food, land restoration and sustainable livelihoods [18,39]. In Western Kenya, the sustainable use of biomass for cooking has an important role to enhance various ecosystem services through the creation of local businesses. Considering the limitations observed to collect social and economic data, the present environmental assessment serves as a first step for conducting a full sustainability assessment on advanced local biomass-based cooking transition options. The environmental assessment is focused on the relevance of introducing renewable energy systems in a developing region of Kenya in the context of the SDGs $[10,41]$.

Considering the limited number of dynamic LCA studies applied to the developing region context, the present study focuses on conducting an environmental impact assessment of the bioenergy transition strategies previously analyzed in an energy modelling study conducted by Carvalho et al. [26]. In line with the previous study, the present research analyzes the environmental sustainability of the energy transition options in relation to a business-as-usual scenario for the time span between 2015 and 2035. The dynamic LCA approach considers the evolution of the household energy mix computed 
in the LEAP model for that time span. The LCA results are presented for both the baseline and end years, considering the projections in the evolution of energy demand and supply until the year 2035, taking into account historical changes in the economy and demographic conditions in the Kisumu County. As in the LEAP study [26], in the present LCA study, the BAU scenario also considers that no policies will be introduced to mitigate environmental impacts of traditional cooking systems. The present LCA also considers the evolution of the household energy demands according to the following biomass/cookstove transition scenarios (Figure 1):

(i) Business as usual, considering the evolution according to historical trends on population growth and urbanization, whereas the use of liquefied petroleum gas (LPG) and electricity will continue the same and the share of traditional cooking systems will be reduced according to historical trends (no transition policies adopted);

(ii) Improved cookstoves combusting wood-logs produced via locally sustainable agroforestry systems (ICS), and biomass briquettes produced with residues with crop residues such as maize cobs;

(iii) Micro-gasifying cookstoves using pelletized fuels made of sugarcane bagasse and woody biomass produced in agroforestry systems (PGS);

(iv) Biogas stoves with household organic waste and animal manure being anaerobically digested to a gaseous mixture including methane $\left(\mathrm{CH}_{4}\right)$ in local biodigestors (BGS);

(v) An Integrated (INT) scenario evaluated a mix of the ICS, PGS and BGS scenarios (Figure 1).

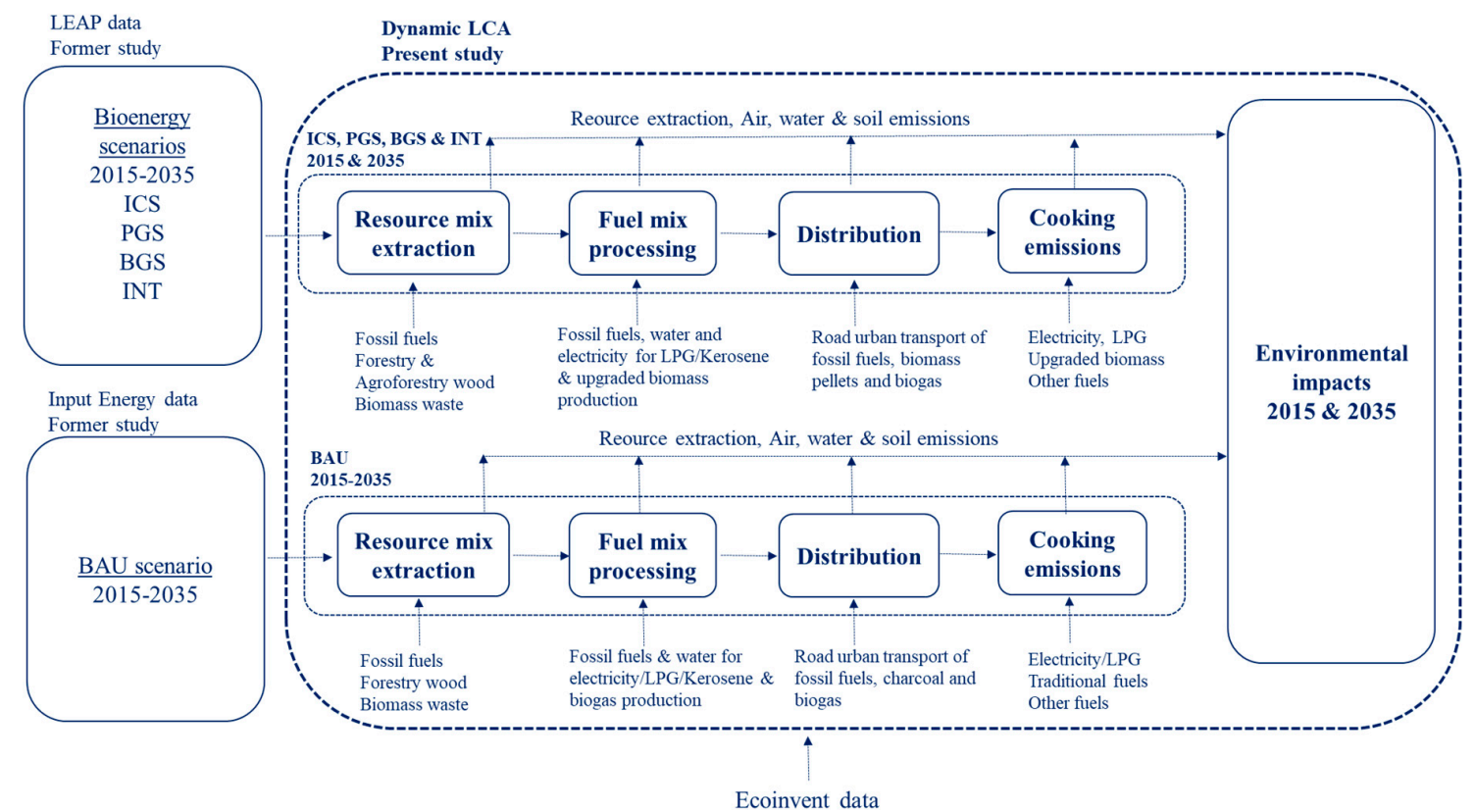

Figure 1. Overall description of the dynamic LCA method applied based on input data generated in the previous LEAP study (Original figure designed by the author).

The LEAP software results are used to conduct the LCA analysis based on the previous energy modelling task, i.e., demand driven (bottom-up) energy model, previously applied for providing energy and emission projections for policy analysis at the regional level [26,42]. The LEAP modelled results used in the LCA are based on technical data provided by the Technology and Environmental Database (TED) coupled to the LEAP software. In this case, the TED is used to calculate emissions from various types of energy systems in Kenyan households [42-44]. The energy demand results used consider the evolution in the household energy use and demographic conditions in the Kisumu County, including different uses of fuel/cookstove systems in the time span between 2015 and 2035 [26]. Considering 
that the present LCA study is based on the same scenarios as those projected in the previous LEAP study conducted by Carvalho et al. [26], this work also considers that policy measures should be implemented before 2035 to promote cleaner and sustainable solutions for renewable energy cooking.

\subsection{Demographic Data}

The main demographic information used to generate the input projection data for the dynamic LCA is the population of the Kisumu County, per capita income in both urban areas and county, the typical household size, number of households in both urban and rural areas, as well as the useful energy demand for cooking and lightning (Table 1).

Table 1. Demographic and energy data of Kisumu County for the baseline year 2015 used by Carvalho et al. [26] to generate the LEAP data to the LCA model [26].

\begin{tabular}{cccc}
\hline Type of Data & Amount & Units & Reference \\
\hline Population & 1155 & 1000 units & {$[45]$} \\
Income/capita & 1.440 & USD & {$[46,47]$} \\
GDP growth/capita & 4.100 & Percent & {$[41]$} \\
Household size & 4.400 & Nr. of people & {$[48]$} \\
Nr. of houses & 227.0 & 1000 units & {$[48]$} \\
Rural houses & 118.0 & 1000 units & {$[48]$} \\
Urban houses & 109.0 & 1000 units & {$[48]$} \\
Peri-urban/total nr. & 60.00 & Percent & {$[49]$} \\
Useful cooking energy demand $^{\text {a }}$ & 0.1200 & TOE & {$[50-52]$} \\
Useful lightning energy demand $^{\text {b }}$ & 2.500 & MWh & {$[53]$} \\
\hline
\end{tabular}

a Based on the average annual useful energy demand for cooking; ${ }^{b}$ Based on the average annual useful energy demand for lightning in a mid-income urban household in Kenya.

This study is based on the fact that the population in the Kisumu County will increase by $99 \%$ in the period between 2015 and 2035. By 2035, the population income per capita is expected to grow up to 2900 USD per year, whereas the income per capita in the city of Kisumu (urban income), is expected to be 1.5 times higher than in both the urban and rural areas of the Kisumu County.

According to the LEAP modelling results [26] used in the LCA model, in the baseline year, the household energy use was over 9 million Gigajoule (GJ), with wood-logs and charcoal being the main cooking fuels used in the year 2015. In the LCA study, it is also considered that, despite the trends in urbanization, a significant part of the peri-urban population is expected to continue living in informal settings with limited access to electricity and LPG.

Thus, the present study stresses the importance of potential life-cycle based environmental improvements associated with the introduction of alternative biomass cookstove strategies in the region. In line with the previous LEAP study, the present LCA study also explores the fact that, by 2035, bottle biogas and biomass pellet cooking systems might be an affordable way for a substantial part of the Kisumu County's population to mitigate environmental impacts related to current traditional cooking practices [26].

\subsection{Resource and Energy Data}

In line with the previous LEAP study [26], the projected use of natural resources and final energy used for cooking and lightning used to model the LCA inputs is computed considering the household energy use patterns in the historical years between 2010 and 2014 [26]. The calculation of the energy use is performed according to each type of cooking and lightning fuel/technology system, in order to model the household energy demands between 2015 and 2035. In the ICS scenario, all the woody biomass used in 2035 is expected to be produced via agroforestry systems considering the available agricultural land in both the Kisumu County and the nearby county of Siaya. As there is no sufficient amount of agricultural land available today that can be converted to agroforestry land systems, in this 
study it is considered that part of the woody biomass produced via agroforestry was sourced by Siaya County. In the PGS, a full replacement of traditional cookstoves by pellet micro-gasifying stoves is expected to occur in the year 2035. In urban areas, the biomass pellets are expected to be produced by a mixture of woody biomass from agroforestry $(50 \%)$ and sugarcane bagasse $(50 \%)$, considering that sugarcane bagasse is the most important crop-residue produced in the industrial sugar belt around the city of Kisumu. In rural areas, biomass pellets are assumed to be fully produced via the densification of woody biomass produced in agroforestry systems. Finally, in the BGS scenario, a full replacement of traditional cookstoves by biogas stoves is projected to occur for the year 2035. Here, half of the biogas is expected to be produced through the anaerobic digestion of animal manure and the other half through the digestion of municipal household waste produced in the Kisumu County. The LEAP functions used to compute the energy data that serves as input data to the LCA model are described in the Eq. 1-3 and Appendix A of the previous research published by Carvalho et al. [26].

\subsection{Life-Cycle Assessment}

After modelling the supply of energy in the various scenarios, the LCA is applied according to the international ISO14040 standard, which defines three main steps to conduct a LCA: (i) Aim and Scope; (ii) Inventory analysis; (iii) Interpretation. This study aims to analyze material and energy flows, and quantify the environmental impacts of distinct bioenergy value-chains for cooking across the life-cycle stages of the different systems, including feedstock collection, processing, distribution and use, as described in Table 2. This study has the final goal of identifying opportunities for environmental improvement, supporting decision makers to understand the sources and magnitudes of impacts throughout the life cycle of each system [31]. Although this study does not include any social and economic assessment of the proposed bioenergy strategies, the application of LCA in this study can be strategic to support environmentally sustainable energy planning policies in the Kisumu County.

Table 2. Bioenergy value-chains for cooking, life cycle stages, assumptions, and source of data based on a previous scenarios established by Carvalho et al. [26,40].

\begin{tabular}{|c|c|c|c|c|c|}
\hline \multirow{2}{*}{\multicolumn{2}{|c|}{ Life Cycle Stages }} & \multicolumn{4}{|c|}{ Policy Option and Bioenergy Value Chains } \\
\hline & & BAU & ICS & PGS & BGS \\
\hline \multirow[t]{2}{*}{$\begin{array}{l}\text { Feedstock } \\
\text { collection }\end{array}$} & Assumption & $\begin{array}{l}\text { Unsustainable } \\
\text { harvesting no } \\
\text { regrowth- } \\
\text { Manual [54] }\end{array}$ & $\begin{array}{c}\text { Sustainable } \\
\text { harvesting } \\
\text { agroforestry- } \\
\text { Manual }[39,54]\end{array}$ & $\begin{array}{c}\text { Sustainable } \\
\text { harvesting of } \\
\text { bagasse and } \\
\text { agroforestry wood- } \\
\text { Manual }[39,54]\end{array}$ & $\begin{array}{l}\text { Sustainable } \\
\text { waste \& } \\
\text { manure } \\
\text { harvesting- } \\
\text { Manual }\end{array}$ \\
\hline & $\begin{array}{c}\text { Ecoinvent processes } \\
\text { adapted } 1,2\end{array}$ & $\begin{array}{l}\text { Residual wood, } \\
\text { dryl market }\end{array}$ & $\begin{array}{l}\text { Residual wood, } \\
\text { dryl market }\end{array}$ & $\begin{array}{c}\text { bagasse straw } \\
(50 \%) / \text { wood pellet } \\
(50 \%) \text { prod| market }{ }^{c}\end{array}$ & $\begin{array}{l}\text { Biogas, from } \\
\text { grass| market }\end{array}$ \\
\hline \multirow[t]{2}{*}{$\begin{array}{l}\text { Feedstock } \\
\text { processing }\end{array}$} & Technology & $\begin{array}{c}\text { Inefficient } \\
\text { charcoal kilns }\end{array}$ & $\begin{array}{l}\text { Efficient char. } \\
\text { kilns }\end{array}$ & $\begin{array}{c}\text { Efficient pelleting } \\
\text { engines }\end{array}$ & $\begin{array}{l}\text { Efficient } \\
\text { municipal } \\
\text { digestors }\end{array}$ \\
\hline & Efficiency/source & $10-15 \%$ & $20 \%$ & $99 \%$ & $50-60 \%$ \\
\hline Distribution & Transport/distance & $\begin{array}{l}\text { Rural: None. } \\
\text { Urban: Bicycle } \\
(30 \mathrm{~km})\end{array}$ & $\begin{array}{l}\text { Rural: None. } \\
\text { Urban: Bicyc. } \\
\quad(30 \mathrm{~km})\end{array}$ & $\begin{array}{l}\text { Rural: None. Urban: } \\
\text { Bicyc. }(30 \mathrm{~km})\end{array}$ & $\begin{array}{l}\text { Rural: None. } \\
\text { Urban: NA }\end{array}$ \\
\hline Use & Cooking efficiency ${ }^{3}$ & $<20 \%$ & $>20-30 \%$ & $30-45 \%$ & $50-60 \%$ \\
\hline
\end{tabular}




\subsubsection{System Boundaries}

In this study, an LCA is performed in function of the cumulative energy demand for the various energy cooking scenarios analyzed in LEAP. The LCA is based on a regionalized inventory and impact assessment from raw material extraction to energy end-use for cooking. The calculations are performed by using the software Simapro 8.5 by applying the ReCiPe method [55].

The study is conducted taking into account the ISO standard $14040[29,56]$, according to the following life-cycle stages (Figure 1):

- Production and transportation of the mix of the cookstove fuel feedstock from the production site to the processing location;

- Processing of the mix of feedstock into a form of ready to be used fuels in cookstoves;

- Distribution of the different types of fuels from the processing locations to the respective retailers or consumers;

- Use of the fuels via their combustion or use of electricity in a cookstove, according to the mix of cooking systems;

\subsubsection{Inventory Analysis}

The inventory analysis is based on data from provided by the LEAP modelling study conducted by Carvalho et al. [26], and information collected from the literature and background data from version 3.1 of the ecoinvent [57] and Agrifootprint databases [57]. In order to compensate for the unavailability of regional Life Cycle Inventory (LCI) data, we permitted the use of direct proxies for certain processes [58]. Some fuel categories (e.g., charcoal, briquettes, wood from unsustainable forest management) are not included in the Ecoinvent database and values have to be approximated (e.g., for charcoal it is assumed that to produce 1 ton of charcoal, 5 tons of wood are necessary). For other fuel categories, e.g., kerosene, biogas and wood pellets only general values (global averages) on raw material extraction and production (upstream processes) are used. The Ecoinvent data processes used in the study are presented in Appendix A (Tables A1-A3).

\subsubsection{Impact Assessment}

The environmental performance of the different transition policy options in the Kimusu County are assessed taking into account the following environmental impact categories: (i) Global warming; (ii) Ozone formation, human health; (iii) Particulate matter formation; (iv) Terrestrial acidification; (v) Water consumption; (vi) Freshwater eutrophication; (vii) Marine eutrophication; (viii) Mineral resource scarcity; (vix) Fossil resource scarcity and (x) Land use. These are considered to reflect the most relevant/critical environmental impacts which can be associated with the combustion of solid-fuels in cookstoves. In this work, the first category is mostly associated with the combustion of fossil and biomass fuels and its effect on the emission of atmospheric pollutants with a global warming potential such as $\mathrm{CH}_{4}, \mathrm{~N}_{2} \mathrm{O}$, carbon monoxide $(\mathrm{CO})$ and particulate matter. The second category is associated with the formation of ozone, which is related to processes that release NOx compounds into the environment. The third process is directly associated with atmospheric emissions from combustion processes, as referred to in the first category. The forth category is associated with the acidification of the soil due to emissions of certain nitrogen compounds such as ammonia $\left(\mathrm{NH}_{3}\right)$ and $\mathrm{NOx}$, which can be associated with the use of chemicals and fertilizers that cause emissions to the soil. The fifth category is related with the consumption of water consumption and availability in the ecosystems and can be associated with its incorporation in industrial processes, which can be specifically used for the production of some chemicals and other materials. The sixth and seventh categories are associated with the excessive presence of certain nutrients in water systems, due to the release of phosphorus and nitrogen compounds, respectively, which can be associated with the use of certain chemicals and fertilizers. The eighth and ninth categories are mostly associated with the extraction of raw materials from nature and the scarcity of these resources. The last category can be associated with relative 
species loss due to the use of land, related to the processes of land transformation, land occupation and land relaxation.

\section{Results}

\subsection{Biomass Resources and Energy Demands}

The Kisumu County has an agro-industrial and municipal organic waste feedstock of over 1.8 million $\mathrm{t}$ biomass (Table 3). The present work assumed that all the mass of biomass feedstock analyzed are suitable for an efficient and sustainable conversion to upgraded cooking fuels such as biomass pellets and biogas.

Table 3. Biomass available in BAU, $2015(\mathrm{t})$ and use in the BAU, ICS, PGS, BGS and INT, 2035 (t).

\begin{tabular}{ccccccc}
\hline & $\begin{array}{c}\text { Availability } \\
\text { BAU, 2015 }\end{array}$ & $\begin{array}{c}\text { Demand } \\
\text { BAU, 2035 }\end{array}$ & $\begin{array}{c}\text { Demand } \\
\text { ICS, 2035 }\end{array}$ & $\begin{array}{c}\text { Demand } \\
\text { PGS, 2035 }\end{array}$ & $\begin{array}{c}\text { Demand } \\
\text { BGS, 2035 }\end{array}$ & $\begin{array}{c}\text { Demand } \\
\text { INT, 2035 }\end{array}$ \\
\hline $\begin{array}{c}\text { Wood-logs } \\
\text { (forest) }\end{array}$ & $1.05 \times 10^{4}$ & $9.28 \times 10^{5}$ & - & - & - & - \\
$\begin{array}{c}\text { Wood-logs } \\
\text { (agrofor.) }\end{array}$ & $5.65 \times 10^{5}$ & - & $1.63 \times 10^{5}$ & $1.34 \times 10^{5}$ & - & $5.60 \times 10^{4}$ \\
Maize cobs & $9.50 \times 10^{5}$ & - & $1.88 \times 10^{5}$ & - & - & $1.40 \times 10^{4}$ \\
S. bagasse & $2.60 \times 10^{5}$ & - & - & $1.05 \times 10^{5}$ & - & $3.10 \times 10^{4}$ \\
$\begin{array}{c}\text { Org. waste } \\
\text { Manure }\end{array}$ & $2.35 \times 10^{5}$ & - & - & - & $2.04 \times 10^{5}$ & $2.00 \times 10^{4}$ \\
Total & $4.26 \times 10^{5}$ & - & - & - & $2.04 \times 10^{5}$ & $2.00 \times 10^{4}$ \\
\hline
\end{tabular}

${ }^{1}$ Considering wood harvesting manual practices unsustainable with no regrowth. ${ }^{2}$ Considering the demand for woody biomass will be produced via sustainable agroforestry systems in the available agricultural land in both the Kisumu (35\%) and Siaya (65\%) Counties. ${ }^{3}$ Potential in the year 2015 to produce wood-logs with the available agricultural land, considering that $10 \%$ of the agricultural land can be converted to agroforestry land and the productivity of $10 \mathrm{t}$ of woody biomass per ha of agroforestry land.

In the BAU scenario, in the year 2035, the demands for wood-logs in the Kisumu County would exceed the forest production capacity and potential agroforestry systems in that scenario and year. In the BAU scenario, in the year 2035, it will be necessary to import around 861 thousand ton of wood-logs from other regions, an amount that corresponds to around $92.8 \%$ of the total use.

According to the ICS scenario, the current capacity for producing woody biomass via sustainable agroforestry systems is able to satisfy $35 \%$ of the future demand of wood-logs. In this scenario, the current availability of feedstocks of maize cobs is sufficient to fulfill $100 \%$ of the demands for briquetting this biomass residue and transform it to a usable cooking fuel (Table 3). In the PGS scenario, the current capacity of agricultural land for the production of woody biomass in sustainable agroforestry systems can satisfy $42 \%$ of the future demands for wood-logs. According to the assumptions and projections made for this scenario, the current availability of sugarcane bagasse is sufficient to satisfy $100 \%$ of the demands for this biomass feedstock to produce sufficient biomass pellets for satisfying the energy cooking demands in 2035. Finally, in both the BGS and INT scenarios, the biomass feedstocks available in 2015 will be sufficient to address $100 \%$ of the demands for the production of wood-logs and upgraded fuels made of various biomass feedstocks considered in those two scenarios.

\subsection{Fuel Energy Inventory Data}

In the BAU scenario, due to population growth and the rate of urbanization, the amount of fuel in terms of energy consumption is expected to increase by over $50 \%$ until 2035 in relation to the baseline year from around 9 to approximately 14 million GJ. This condition is related to the fact that there will be more people with energy needs and a higher fraction of the population consuming charcoal in urban areas, in case no policy is adopted to change the patterns of energy usage for cooking. In the ICS scenario, the projected increase in the energy consumption is expected to smoothen in relation to the 
BAU, since the energy consumption by 2035 will be in the order of 13 million GJ (Figure 2). In the PGS scenario, the energy consumption is expected to increase by $26 \%$ in the period between 2015 and 2035 , reaching a value in the order of 12 million GJ. The smallest increase in the energy consumption is predicted for 2035 in the BGS scenario, being this in the order of $8 \%$. In the INT scenario, the energy consumption is expected to increase by $20 \%$ to 11 million GJ in 2035 .

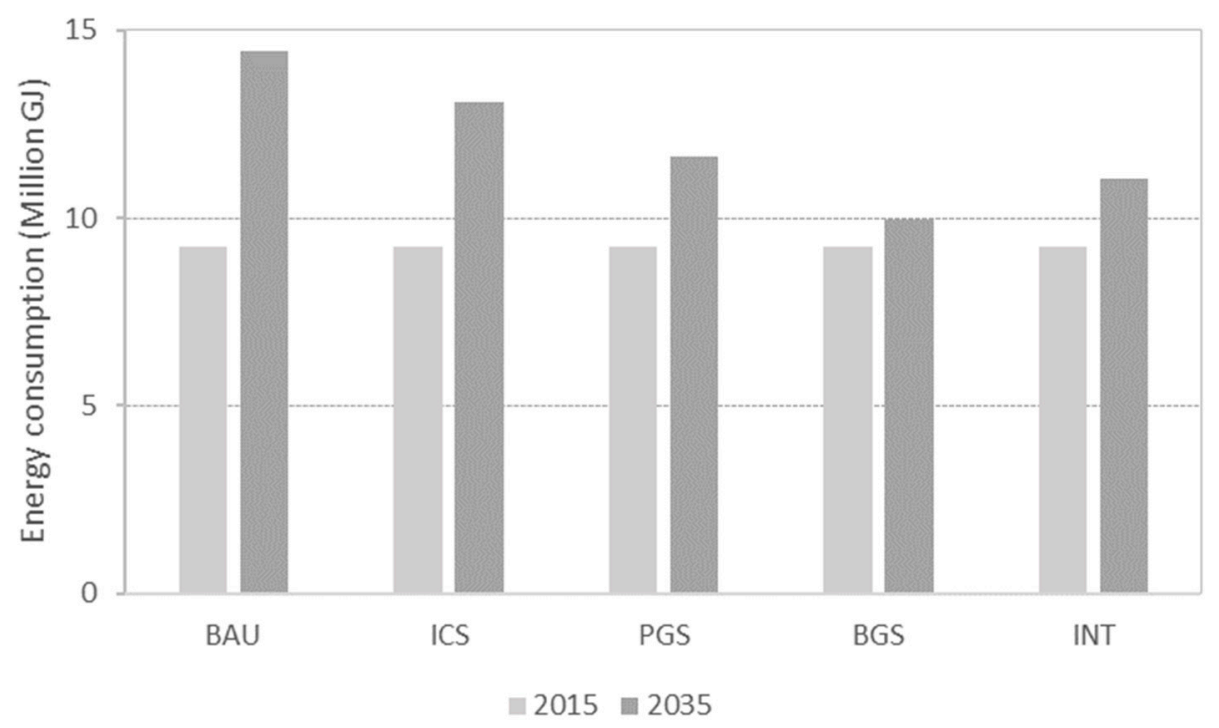

Figure 2. Fuel use in terms of energy consumption as input for the LCA model in the BAU, ICS, PGS, BGS and INT scenarios in 2015 and 2035.

In the BAU scenario, the greenhouse gas (GHG) emissions are expected to increase by $10 \%$, ranging from around 220 thousand $t$ of $\mathrm{CO}_{2 \mathrm{e}}$ in 2015 to around 245 thousand $\mathrm{t}$ of $\mathrm{CO}_{2 \mathrm{e}}$ in 2035. In the ICS scenario, the GHG emissions are predicted to be reduced by $18 \%$ to a value around 180 thousand $t$ of $\mathrm{CO}_{2 \mathrm{e}}$ in 2035 (Figure 2). The amount of fuel input flows to the LCA model regarding $t$ fuel production and cooking life-cycle stages by type of fuel/cooking system in each scenario, are respectively described in detail in the Appendix A (Tables A2 and A4).

\subsection{Environmental Impact Assessment}

In the BAU scenario, in the year 2015, approximately $62 \%$ of the use of household energy for cooking was associated with the use of open fires, whereas the use of charcoal represents $27 \%$ of the residential energy consumption for cooking, and the use of kerosene stoves represents $6 \%$ of the energy use for cooking (Figure 3).

In the BAU scenario, the LCA results also reflect the effects of population growth and increasing urbanization in Western Kenya between 2015 and 2035 with an increase of $96 \%$ in all impact categories (Figure 3; Table 4). In this scenario, with the increased urbanization, an increased number of households is expected to have access to charcoal for cooking, reducing the direct exposure to certain household air pollutants. However, the LCA results also reflect that this improvement is not reflected in an overall reduction of environmental impacts, a fact that can be associated with the low thermochemical conversion performance of charcoal kilns. 


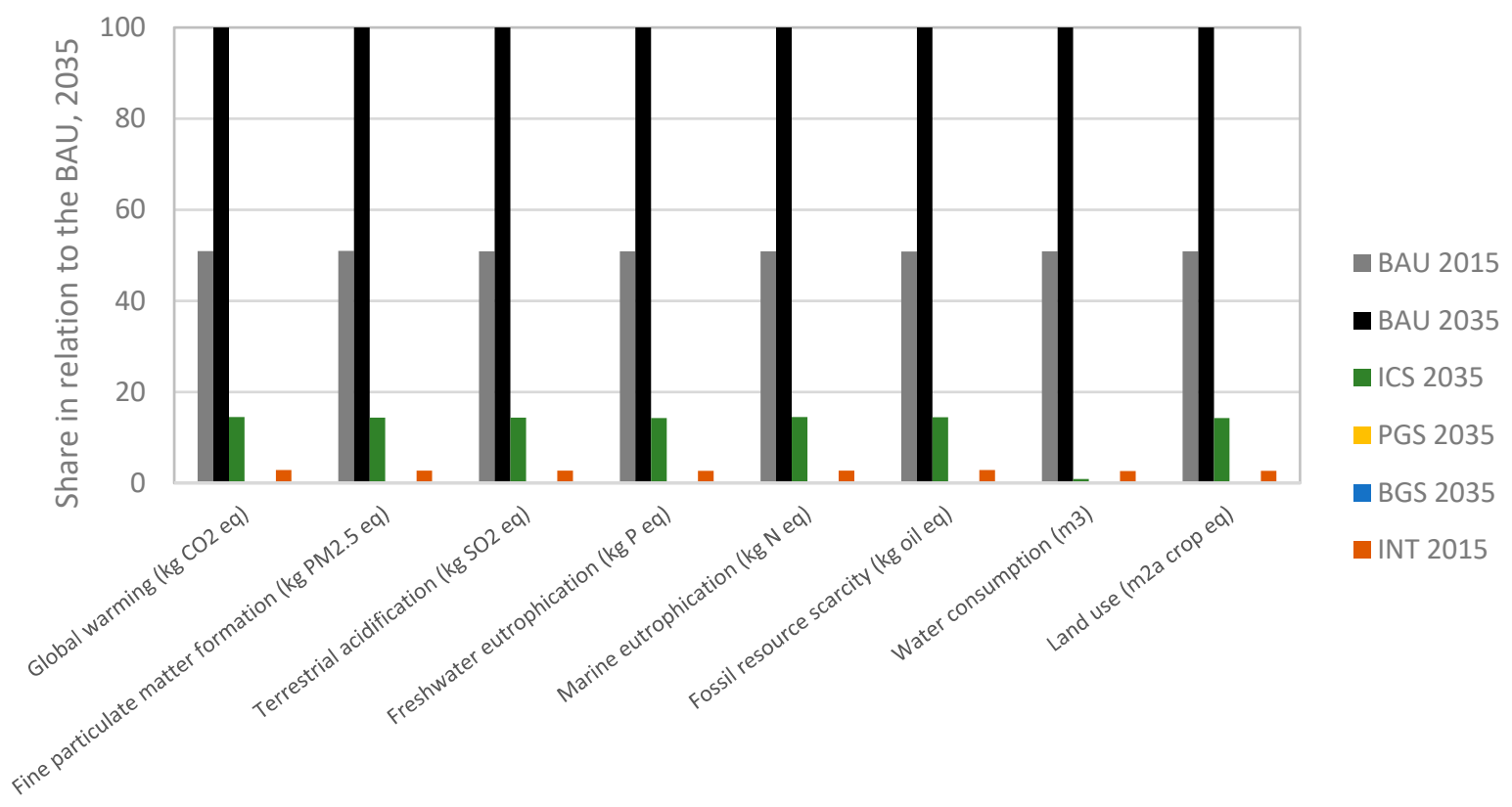

Figure 3. Environmental impacts in the BAU 2015, ICS 2035, PGS 2035, BGS 2035 and INT 2035 scenarios in relation to the BAU scenario, according to the percentage determined in the BAU 2035 scenario.

Table 4. Environmental impacts based on critical ReCiPe categories which are associated with biomass cooking activities in the Kisumu County in the BAU scenario in the years 2015 and 2035.

\begin{tabular}{|c|c|c|}
\hline Impact Categories ${ }^{1}$ & BAU 2015 & BAU 2035 \\
\hline Global warming $\left(\mathrm{kg} \mathrm{CO}_{2 \mathrm{eq}}\right)$ & $3.4 \times 10^{10}$ & $6.7 \times 10^{10}$ \\
\hline Fine particulate matter formation $\left(\mathrm{kg} \mathrm{PM}_{2.5 \mathrm{eq}}\right)$ & $1.5 \times 10^{8}$ & $3.0 \times 10^{8}$ \\
\hline Terrestrial acidification $\left(\mathrm{kg} \mathrm{SO}_{2 \mathrm{eq}}\right)$ & $1.5 \times 10^{8}$ & $3.0 \times 10^{8}$ \\
\hline Freshwater eutrophication $\left(\mathrm{kg} \mathrm{P}_{\mathrm{eq}}\right)$ & $9.5 \times 10^{6}$ & $1.9 \times 10^{7}$ \\
\hline Marine eutrophication $(\mathrm{kg} \mathrm{N}$ eq $)$ & $8.9 \times 10^{5}$ & $1.7 \times 10^{6}$ \\
\hline Fossil resource scarcity (kg oil $\mathrm{eq}$ ) & $1.1 \times 10^{10}$ & $2.1 \times 10^{10}$ \\
\hline Water consumption $\left(\mathrm{m}^{3}\right)$ & $6.7 \times 10^{8}$ & $1.3 \times 10^{9}$ \\
\hline Land use $\left(\mathrm{m}^{2} \mathrm{a}\right.$ crop $\left.\mathrm{eq}\right)$ & $9.4 \times 10^{10}$ & $1.9 \times 10^{11}$ \\
\hline
\end{tabular}

${ }^{1}$ Calculated according to the ReCiPe method [55].

The impact of the introduction of improved cookstoves in the ICS scenario is predicted to contribute to the reduction of the effect of household energy activities on "Global warming", "Fine particulate matter formation", "Terrestrial acidification", "Freshwater eutrophication", "Marine water eutrophication", "Fossil resource scarcity", "Water consumption" and "Land use" between 80 and 90\% in relation to the BAU scenario in the year 2035. Additionally, the introduction of advanced gasifier cookstoves combusting pelletized fuels is expected to reduce the environmental impacts of all the referred categories by over $98 \%$ in relation to the BAU 2035 scenario (Figure 3; Table 5). Furthermore, the replacement of traditional cookstoves by biogas stoves is predicted to reduce those impacts by the same order of magnitude as in the previous scenario. In the INT scenario, the environmental impacts associated with the analyzed impact categories are expected to be around $97 \%$ lower than those observed in the BAU scenario in 2035 (Figure 3; Table 5).

In the year 2035, and for the ICS scenario, the introduction of ICSs using wood-logs produced in agroforestry systems will contribute to an over $80 \%$ reduction in all the environmental impacts analyzed in this study in relation to the BAU scenario. Such improvements are partly associated with the fact that the improved cookstoves are around twice more efficient than traditional cooking systems, which results in significant fuel savings. Additionally, the use of woody biomass produced in a more sustainable way is expected to reduce the pressure on natural ecosystems. However, despite reflecting 
the reduction in the harvesting of woody biomass from Kenyan forests, the life cycle inventory in this study does not account for the positive environmental impacts related to the introduction of agroforestry systems, i.e., those impacts associated with the preservation of biodiversity and possible land-use changes (LUCs), due to limitations in accessing to real datasets that can reflect certain localities. Such environmental aspects are not accounted in the life-cycle inventory for scenarios of biodiversity losses and LUCs enhanced by the rate of deforestation associated with higher consumption of woody biomass from the forests. In the same year, for both the PGS and BGS scenarios, and for all analyzed impact categories, the introduction of the advanced cookstove systems in 2035 will contribute to reducing the environmental impacts by over $90 \%$ in relation to the BAU scenario in 2035 . In a similar way, the technology advancements allow the achievement of even higher thermal energy conversion efficiencies in relation to traditional systems. Beyond that, these scenarios result from the utilization of biomass residues in micro-gasifier and biogas cookstoves, which are going to either be disposed of in natural environment or inefficiently burned in open fields if no measures are introduced. Furthermore, in this study, no environmental impacts are allocated to the upcycled biomass residues (i.e., sugarcane bagasse, animal manure and organic waste), which explains the fact that these two biomass/fuel systems have a higher environmental performance than the improved cookstoves. Finally, in the INT scenario, the adoption of the mixed biomass cookstove strategies is expected to contribute to reduce the environmental impacts by a value between $94 \%$ and $95 \%$ (Table 5).

Table 5. Environmental impacts based on critical ReCiPe categories which are associated with biomass cooking activities in the Kisumu County in the ICS, PGS, BGS and INT scenarios in 2035.

\begin{tabular}{|c|c|c|c|c|}
\hline Impact Categories ${ }^{1}$ & ICS 2035 & PGS 2035 & BGS 2035 & INT 2035 \\
\hline Global warming $\left(\mathrm{kg} \mathrm{CO}_{2 \mathrm{eq}}\right)$ & $9.7 \times 10^{9}$ & $2.1 \times 10^{8}$ & $1.6 \times 10^{8}$ & $1.9 \times 10^{9}$ \\
\hline Fine particulate matter format. $\left(\mathrm{kg} \mathrm{PM}_{2.5 \mathrm{eq}}\right)$ & $4.3 \times 10^{7}$ & $4.3 \times 10^{5}$ & $2.7 \times 10^{5}$ & $8.2 \times 10^{6}$ \\
\hline Terrestrial acidification $\left(\mathrm{kg} \mathrm{SO}_{2 \mathrm{eq}}\right)$ & $4.3 \times 10^{7}$ & $5.1 \times 10^{5}$ & $3.8 \times 10^{5}$ & $8.2 \times 10^{6}$ \\
\hline Freshwater eutrophication $\left(\mathrm{kg} \mathrm{P}_{\mathrm{eq}}\right)$ & $2.7 \times 10^{6}$ & $2.6 \times 10^{4}$ & $6.1 \times 10^{3}$ & $5.0 \times 10^{5}$ \\
\hline Marine eutrophication $\left(\mathrm{kg} \mathrm{N}_{\mathrm{eq}}\right)$ & $2.5 \times 10^{5}$ & $4.1 \times 10^{3}$ & $5.6 \times 10^{2}$ & $4.8 \times 10^{4}$ \\
\hline Fossil resource scarcity (kg oil $\mathrm{eq}_{\mathrm{eq}}$ ) & $3.0 \times 10^{9}$ & $5.8 \times 10^{7}$ & $4.8 \times 10^{7}$ & $5.9 \times 10^{8}$ \\
\hline Water consumption $\left(\mathrm{m}^{3}\right)$ & $1.9 \times 10^{7}$ & $7.9 \times 10^{5}$ & $3.3 \times 10^{5}$ & $3.5 \times 10^{7}$ \\
\hline Land use $\left(\mathrm{m}^{2} \mathrm{a}\right.$ cropeq $)$ & $2.6 \times 10^{10}$ & $4.0 \times 10^{8}$ & $4.5 \times 10^{5}$ & $5.0 \times 10^{9}$ \\
\hline
\end{tabular}

${ }^{1}$ Calculated according to the ReCiPe method [55].

In this study, a small difference is observed for the variations in the environmental impacts of the different biomass cookstove transition measures in relation to the BAU scenario in the year 2035 . However, it is possible to observe that the BGS and PGS scenarios are the ones with higher reduction of the environmental impacts in relation to the analyzed categories. This result follows the trend observed for the evolution of the GHG emissions as shown in a previous study conducted by Carvalho et al. [26]. These environmental improvements can mostly be explained by the high efficiency of the thermochemical conversion processes associated with the combustion of biogas and pelletized fuels, which has a significant potential effect on reducing impacts such as on those associated with "Global warming", "Fine particulate matter formation", "Water consumption" and "Land use".

\section{Conclusions}

Considering the premise that local-based and renewable energy solutions are needed in the short to medium term to address HAP in developing countries, this study shows that the transition to biogas and micro-gasifying cookstove systems combusting upgraded biofuels, i.e., biogas and biomass pellets, greatly contributes to reducing critical environmental impacts beyond deforestation and HAP associated with a potential future phase out of traditional cooking practices in Western Kenya. In the BGS scenario, the availability of animal manure and organic waste in the year 2015 (661 thousand t) is $4 \%$ higher than the expected consumption of this feedstock in the year 2035 (408 thousand $t$ ). In the PGS scenario, the availability of agricultural land to produce agroforestry woody biomass in the 
Kisumu County in 2015 (around 57 thousand $t$ ) is not sufficient to satisfy the projected demands for this feedstock in the year 2035 (around $134 \mathrm{t}$ ); imports from the neighboring county of Siaya should be considered to adjust future supply and demand. Additionally, in this scenario, the amount of sugarcane bagasse available in 2015 ( 260 thousand $t$ ) is more than enough to satisfy $100 \%$ of the demands for this feedstock in the projected PGS scenario in the year 2035 (around 105 thousand $\mathrm{t}$ ).

Overall, the LCA confirms the hypothesis of increasing the environmental sustainability of current cooking systems and related fuel value-chains in Western Kenya through the introduction of advanced cookstoves combusting either biogas (BGS scenario) or pelletized fuels (PGS scenario). Such measures are expected to reduce by over $80 \%$ the environmental impacts for all the referred categories analyzed in relation to the BAU scenario in the year 2035. Although this study has demonstrated the great environmental benefits of the suggested measures, further studies are required to consolidate this sustainability assessment through the performance of both social and economic assessments of the proposed valorization alternatives.

By showing that biogas and pellet fuel/advanced cookstove value-chains are viable in terms of the mitigation of the environmental impacts, this study may orient the scientific community and energy sector stakeholders about the environmental benefits of such valorization and energy efficiency alternatives at the sub-national level. As the suggested bioenergy cooking strategies mitigate a wide range of life-cycle environmental impacts beyond HAP, an interesting and specifically relevant area for future research is related to the analysis of the environmental externalities (e.g., on human health) associated with the mitigation of greenhouse gas and PM emissions in Western Kenya. In such a context, this study does not yet fully provide consolidated recommendations to decision-makers responsible for designing energy policies in the Kisumu County, which will only be possible after a solid socio-economic assessment is carried out.

Future work in this area is highly relevant in order to provide key recommendations not only for policy makers, but also for local biomass industries, which could be interested in capitalizing investments in alternate value-chains. Furthermore, government incentives for the deployment of innovative logistical systems and tax credits-including the deployment of advanced biomass valuation alternatives and cookstove via local community-based projects-present a potential to enhance sustainable livelihoods through bottom-up policies design with the participation of the population.

Author Contributions: R.L.C., corresponding author, worked on the conceptualization, methodology, formal analysis, data collection and writing of the original draft. P.Y., V.K.K.U. and D.A. collaborated with R.C. in the modelling work with the software LEAP and Simapro. They also collaborated in the validation of the results in collaboration with the other co-authors. C.B., G.N., N.G.-L., R.L. and R.D.-C. contributed to the conceptualization of the work and writing review and editing. C.B. and D.A. were responsible for the project administration and supervised the work conducted in collaboration with the other co-authors. They were also involved in funding acquisition for the achievement of the goals of this research. All authors have read and agreed to the published version of the manuscript.

Funding: This research was funded by the Swedish Research Council FORMAS through the project Sustainable Biomass Utilization in Sub-Saharan Africa for an Improved Environment and Health, Dnr. 942-2015-1385. The work conducted by the researcher Ricardo Carvalho was financed by the Postdoctoral grant number JCK-1516, funded by the Kempe Foundation, and thanks are also due to FCT/MCTES for the financial support to CESAM (UID/AMB/50017/2019), through Portuguese national funds. The LCA work was financed by Bio4Energy, a strategic research environment appointed by the Swedish government.

Acknowledgments: Part of the work conducted by Ricardo Carvalho was funded with the technical support of the Group of Energy and Environment of the Federal Institute of Education, Science and Technology of Ceará, where the researcher is integrated.

Conflicts of Interest: The authors declare no conflict of interest.

\section{Appendix A}

Information about the inventory data for the LCA are presented in the tables below. 
Table A1. Dataset used from the Ecoinvent database related to the LCA study in every fuel.

\begin{tabular}{|c|c|}
\hline System & Ecoinvent Database Unit Process Used \\
\hline Openfire wood & Residual wood, dry $\{$ GLO $\} \mid$ market for $\mid$ APOS, U \\
\hline ICS wood & Residual wood, dry $\{$ GLO $\} \mid$ market for $\mid$ APOS, U \\
\hline Kerosene & Kerosene $\{$ RoW $\} \mid$ market for $\mid$ APOS, U \\
\hline Trad charcoal ${ }^{1}$ & Residual wood, dry $\{$ GLO $\} \mid$ market for $\mid$ APOS, $U$ \\
\hline Impro charcoal ${ }^{1}$ & Residual wood, dry $\{$ GLO $\} \mid$ market for $\mid$ APOS, $U$ \\
\hline Electric & Market for electricity, medium voltage KE \\
\hline LPG & Liquefied petroleum gas $\{$ RoW $\} \mid$ market for| APOS, U \\
\hline ICS briquette residue & $\begin{array}{l}\text { Wood pellet, measured as dry mass }\{\text { RoW }\} \mid \text { market for wood } \\
\text { pellet } \mid \text { APOS, } U\end{array}$ \\
\hline ND-gasifier biomass pellets $(50 / 50)^{1}$ & $\begin{array}{c}\text { Straw, stand-alone production }\{\text { GLO }\} \mid \text { market for } \mid \text { APOS, } U \\
(50 \%) / \text { Wood pellet, measured as dry mass }\{\text { RoW }\} \mid \text { market for } \\
\text { wood pellet } \mid \text { APOS, U }(50 \%\end{array}$ \\
\hline FD-gasifier biomass pellets $(50 / 50)^{1}$ & $\begin{array}{c}\text { Straw, stand-alone production }\{\text { GLO }\} \mid \text { market for } \mid \text { APOS, U } \\
(50 \%) / \text { Wood pellet, measured as dry mass }\{\text { RoW }\} \mid \text { market for } \\
\text { wood pellet } \mid \text { APOS, U }(50 \%)\end{array}$ \\
\hline ND-gasifier wood pellets & $\begin{array}{l}\text { Wood pellet, measured as dry mass }\{\text { RoW }\} \mid \text { market for wood } \\
\text { pellet } \mid \text { APOS, } U\end{array}$ \\
\hline FD-gasifier wood pellets & $\begin{array}{l}\text { Wood pellet, measured as dry mass }\{\text { RoW }\} \mid \text { market for wood } \\
\text { pellet } \mid \text { APOS, } U\end{array}$ \\
\hline Biogas digester & Biogas, from grass $\{\mathrm{GLO}\} \mid$ market for| APOS, $\mathrm{U}$ \\
\hline Biogas stove & Biogas, from grass $\{G L O\} \mid$ market for $\mid$ APOS, $U$ \\
\hline
\end{tabular}

Table A2. Energy inputs in the fuel production life-cycle stage (TJ), considering each fuel system.

\begin{tabular}{|c|c|c|c|c|c|c|}
\hline Year & 2015 & & & Year 2 & & \\
\hline System & BAU & BAU & ICS & PGS & BGS & INT \\
\hline Unsustainable wood $^{1}$ & 5280 & 4462 & - & - & - & - \\
\hline $\begin{array}{l}\text { Sustainable wood } \\
\text { (agroforestry) }^{2}\end{array}$ & - & - & 2927 & - & - & 565.0 \\
\hline Kerosene & 2185 & 1624 & 1624 & 1624 & 1624 & 1624 \\
\hline Charcoal & 1146 & 3152 & - & - & - & - \\
\hline Electricity & 470.1 & 2955 & 2955 & 2955 & 2955 & 2955 \\
\hline LPG & 90.30 & 1039 & 1039 & 1039 & 1039 & 1039 \\
\hline Maize cobs & - & - & 3391 & - & - & 569.6 \\
\hline Sugarcane Bagasse & - & - & - & 3781 & - & 1121 \\
\hline $\begin{array}{l}\text { Wood-chips } \\
\text { (agroforestry) }\end{array}$ & - & 4462 & - & - & - & - \\
\hline Animal manure & 23.10 & - & 2927 & - & - & 565.0 \\
\hline Municipal waste & - & 1624 & 1624 & 1624 & 1624 & 1624 \\
\hline
\end{tabular}


Table A3. Material/distance inputs in the fuel transport life-cycle stage $\left(\mathrm{tkm}^{1}\right)$ for each fuel system in urban areas.

\begin{tabular}{ccccccc}
\hline Year & $\mathbf{2 0 1 5}$ & \multicolumn{5}{c}{ End Year 2035 } \\
\hline System & BAU & BAU & ICS & PGS & BGS & INT \\
\hline Wood & $6.43 \times 10^{6}$ & $3.86 \times 10^{6}$ & $2.53 \times 10^{6}$ & - & - & $3.33 \times 10^{2}$ \\
Briquettes & $2.97 \times 10^{5}$ & - & $5.35 \times 10^{6}$ & - & - & $8.49 \times 10^{5}$ \\
Charcoal & $4.20 \times 10^{4}$ & $2.30 \times 10^{6}$ & - & - & - & - \\
Biomass & $9.00 \times 10^{3}$ & - & - & $6.30 \times 10^{6}$ & - & $1.87 \times 10^{6}$ \\
pellets & & & - & - & $3.06 \times 10^{6}$ & $1.22 \times 10^{6}$ \\
Biogas & $2.40 \times 10^{4}$ & - & - & & $6.18 \times 10^{5}$ & $6.18 \times 10^{5}$ \\
cylinder & $6.43 \times 10^{6}$ & $6.18 \times 10^{5}$ & $6.18 \times 10^{5}$ & $6.18 \times 10^{5}$ & $6.18 \times 10^{5}$ \\
LPG & $2.97 \times 10^{5}$ & $4.92 \times 10^{5}$ & $4.92 \times 10^{5}$ & $4.92 \times 10^{5}$ & $4.92 \times 10^{5}$ & $4.92 \times 10^{5}$ \\
Kerosene & & - & & & - & \\
\hline
\end{tabular}

${ }^{1}$ Considering the average distribution distance of $30 \mathrm{~km}$ from the production areas to the households.

Table A4. Energy inputs in the cooking life-cycle stage (TJ), considering each cooking system.

\begin{tabular}{|c|c|c|c|c|c|c|}
\hline \multirow{2}{*}{$\begin{array}{c}\text { Year } \\
\text { System }\end{array}$} & \multirow{2}{*}{$\begin{array}{l}2015 \\
\text { BAU }\end{array}$} & \multicolumn{5}{|c|}{ End Year 2035} \\
\hline & & BAU & ICS & PGS & BGS & INT \\
\hline Openfire wood & 5067 & 4178 & - & - & - & - \\
\hline ICS wood & 203.4 & 284.0 & 2895 & - & - & 532.6 \\
\hline Kerosene & 237.6 & 725.7 & 725.7 & 725.7 & 725.7 & 725.7 \\
\hline Trad charcoal & 433.8 & 1320 & - & - & - & - \\
\hline Impro charcoal & 575.8 & 1832 & - & - & - & - \\
\hline Electric & 19.30 & 524.7 & 524.7 & 524.7 & 524.7 & 524.7 \\
\hline LPG & 74.10 & 532.8 & 532.8 & 532.8 & 532.8 & 532.8 \\
\hline ICS briquette residue & - & - & 3391 & - & - & 569.6 \\
\hline ND-gasifier biomass pellets $(50 / 50)^{1}$ & - & - & - & 968.0 & - & 399.3 \\
\hline FD-gasifier biomass pellets $(50 / 50)^{1}$ & - & - & - & 2813 & - & 721.6 \\
\hline ND-gasifier wood pellets & - & - & - & 879.9 & - & 333.5 \\
\hline FD-gasifier wood pellets & - & - & - & 158.4 & - & 52.80 \\
\hline Biogas digester & 23.10 & 79.80 & 79.80 & 79.80 & 1299 & 930.4 \\
\hline Biogas stove & 5067 & - & - & - & 1939 & 768.8 \\
\hline
\end{tabular}

${ }^{1}$ Biomass pellets are a mixture of biomass residues with $50 \%$ bagasse and $50 \%$ woody biomass produced in agroforestry systems.

\section{References}

1. Bonjour, S.; Adair-Rohani, H.; Wolf, J.; Bruce, N.G.; Mehta, S.; Prüss-Ustün, A.; Lahiff, M.; Rehfuess, E.A.; Mishra, V.; Smith, K.R. Solid fuel use for household cooking: Country and regional estimates for 1980-2010. Environ. Health Perspect. 2013, 121, 784-790. [CrossRef] [PubMed]

2. Lim, S.S.; Vos, T.; Flaxman, A.D.; Danaei, G.; Shibuya, K.; Adair-Rohani, H.; Amann, M.; Anderson, H.R.; Andrews, K.G.; Aryee, M.; et al. A comparative risk assessment of burden of disease and injury attributable to 67 risk factors and risk factor clusters in 21 regions, 1990-2010: A systematic analysis for the Global Burden of Disease Study 2010. Lancet 2012, 380, 2224-2260. [CrossRef]

3. Chafe, Z.; Brauer, M.; Héroux, M.; Klimont, Z.; Lanki, T.; Salonen, R.O.; Smith, K.R. Residential Heating with Wood and Coal: Health Impacts and Policy Options in Europe and North America; World Health Organization: Copenhagen, Denmark, 2015.

4. Rehfuess, E. Fuel for Life: Household Energy and Health; Geneva World Health Organization: Geneva, Switzerland, 2006; pp. 1-23. Available online: http://www.who.int/indoorair/publications/fuelforlife/en/ (accessed on 6 February 2020).

5. UNICEF. Clear the Air for Children-The Impact of Air Pollution on Children; UNICEF: New York, NY, USA, 2016; ISBN 1904097243.

6. Sanches-Pereira, A.; Tudeschini, L.G.; Coelho, S.T. Evolution of the Brazilian residential carbon footprint based on direct energy consumption. Renew. Sustain. Energy Rev. 2016, 54, 184-201. [CrossRef] 
7. Felix, M.; Gheewala, S.H. A review of biomass energy dependency in Tanzania. Energy Procedia 2011, 9, 338-343. [CrossRef]

8. Clough, L. The Improved Cookstove Sector in East Africa: Experience from the Developing Energy Enterprise Programme (DEEP); GVEP-Global Village Energy Partnership International: London, UK, 2012; p. 108.

9. Rosenthal, J.; Quinn, A.; Grieshop, A.P.; Pillarisetti, A.; Glass, R.I. Clean cooking and the SDGs: Integrated analytical approaches to guide energy interventions for health and environment goals. Energy Sustain. Dev. 2018, 42, 152-159. [CrossRef] [PubMed]

10. United Nations. Transforming Our World: The 2030 Agenda for Sustainable Development; United Nations: New York, NY, USA, 2015.

11. Johnson, O.; Wanjiru, H.; Ogeya, M.; Johnsson, F.; van Klaveren, M.; Dalla Longa, F. Energising Kenya' s Future: Reducing Greenhouse Gas Emissions and Achieving Development Aspirations; Stockholm Environment Institute: Nairobi, Kenya, 2017.

12. Ouedraogo, N.S. Africa energy future: Alternative scenarios and their implications for sustainable development strategies. Energy Policy 2017, 106, 457-471. [CrossRef]

13. Dalla Longa, F.; van der Zwaan, B. Do Kenya's climate change mitigation ambitions necessitate large-scale renewable energy deployment and dedicated low-carbon energy policy? Renew. Energy 2017, 113, 1559-1568. [CrossRef]

14. Government of Kenya (Ministry of Energy and Petroleum). Ministry of Energy and Petroleum Draft National Energy and Petroleum Policy; Government of Kenya: Nairobi, Kenya, 2015; pp. 1-130.

15. World Health Organization (WHO). Kenya: Country Profile of Environmental Burden of Disease; WHO: Geneva, Switzerland, 2009; p. 1.

16. Global Alliance for Clean Cookstoves. Kenya Country Action Plan; Global Alliance for Clean Cookstoves: Washington, DC, USA, 2013; pp. 1-30.

17. Institute for Health Metrics and Evaluation. Global Burden Disease Compare, Seattle, WA. Available online: https://vizhub.healthdata.org/gbd-compare/ (accessed on 6 February 2020).

18. Food and Agriculture Organization of the United Nations. Agroforestry for Landscape Restoration; Food and Agriculture Organization of the United Nations: Rome, Italy, 2017.

19. African Smallholder Farmers Group (ASFG). Supporting Smallholder Farmers in Africa: A Framework for an Enabling Environment; African Smallholder Farmers Group: London, UK, 2013.

20. Berazneva, J.; Lee, D.; Place, F.; Jakubson, G. Allocation and Valuation of Non-Marketed Crop Residues in Smallholder Agriculture: The Case of Maize Residues in Western Kenya. Ecol. Econ. 2017, 152, 1-21.

21. Ministry of Energy and Petroleum. Draft Strategy and Action Plan for Bioenergy and LPG Development in Kenya; Ministry of Energy and Petroleum: Nairobi, Kenya, 2015; pp. 1-8.

22. Dietz, T.; Börner, J.; Förster, J.J.; von Braun, J. Governance of the bioeconomy: A global comparative study of national bioeconomy strategies. Sustainability 2018, 10, 3190. [CrossRef]

23. Murphy, J.; Bochmann, G. IEA Bioenergy_Task 37: Biogas from Crop Digestion; International Energy Agency: Paris, France, 2011; Volume 37, pp. 1-23.

24. SE4ALL. Sustainable Energy For All-Kenya Action Agenda; 2016; pp. i-64.

25. Carvalho, R.L.; Jensen, O.M.; Tarelho, L.A.C. Mapping the performance of wood-burning stoves by installations worldwide. Energy Build. 2016, 127. [CrossRef]

26. Carvalho, R.L.; Lindgren, R.; García-López, N.; Nyambane, A.; Nyberg, G.; Diaz-Chavez, R.; Boman, C. Household air pollution mitigation with integrated biomass/cookstove strategies in Western Kenya. Energy Policy 2019, 131, 168-186. [CrossRef]

27. Njenga, M.; Iiyama, M.; Jamnadass, R.; Helander, H.; Larsson, L.; de Leeuw, J.; Neufeldt, H.; Röing de Nowina, K.; Sundberg, C. Gasifier as a cleaner cooking system in rural Kenya. J. Clean. Prod. 2015, 121, 208-217. [CrossRef]

28. Torres-Rojas, D.; Lehmann, J.; Hobbs, P.; Joseph, S.; Neufeldt, H. Biomass availability, energy consumption and biochar production in rural households of Western Kenya. Biomass Bioenergy 2011, 35, 3537-3546. [CrossRef]

29. International Standard Organization ISO 14040:2006-Environmental Management-Life Cycle Assessment-Principles and Framework. Available online: https://www.iso.org/standard/37456.html (accessed on 24 February 2019). 
30. Global Alliance for Clean Cookstoves. Comparative Analysis of Fuels for Cooking; Global Alliance for Clean Cookstoves: New York, NY, USA, 2016.

31. Okoko, A.; Reinhard, J.; von Dach, S.W.; Zah, R.; Kiteme, B.; Owuor, S.; Ehrensperger, A. The carbon footprints of alternative value chains for biomass energy for cooking in Kenya and Tanzania. Sustain. Energy Technol. Assess. 2016, 22, 124-133. [CrossRef]

32. Su, S.; Li, X.; Zhu, Y.; Lin, B. Dynamic LCA framework for environmental impact assessment of buildings. Energy Build. 2017, 149, 310-320. [CrossRef]

33. García-Gusano, D.; Iribarren, D.; Dufour, J. Is coal extension a sensible option for energy planning? A combined energy systems modelling and life cycle assessment approach. Energy Policy 2018, 114, 413-421. [CrossRef]

34. Smith, K.R. Cleaning up fuels in two fronts. Nature 2014, 511, 2014. [CrossRef]

35. Hossain, N.; Zaini, J.; Meurah, T.; Mahlia, I. Life cycle assessment, energy balance and sensitivity analysis of bioethanol production from microalgae in a tropical country. Renew. Sustain. Energy Rev. 2019, 115, 1-14. [CrossRef]

36. García-sánchez, M.; Güereca, L.P. Environmental and social life cycle assessment of urban water systems: The case of Mexico City. Sci. Total Environ. 2019, 693, 1-15. [CrossRef]

37. Albertí, J.; Brodhag, C.; Fullana-i-palmer, P. First steps in life cycle assessments of cities with a sustainability perspective: A proposal for goal, function, functional unit, and reference flow. Sci. Total Environ. 2019, 646, 1516-1527. [CrossRef]

38. Ståhl, L.; Nyberg, G.; Högberg, P.; Buresh, R.J. Effects of planted tree fallows on soil nitrogen dynamics, above-ground and root biomass, N2-fixation and subsequent maize crop productivity in Kenya. Plant Soil 2002, 243, 103-117. [CrossRef]

39. Carvalho, R.; Yadav, P.; Lindgren, R.; García-López, N.; Nyberg, G.; Diaz-Chavez, R.; Upadhyayula, V.K.; Boman, C.; Athanassiadis, D. Bioenergy strategies to address deforestation and household air pollution in Western Kenya. In Proceedings of the 27th European Biomass Conference and Exibihition 2019, Lisbon, Portugal, 27 May 2019.

40. Peša, I. Sawdust pellets micro gasifying cook stoves and charcoal in urban Zambia: Understanding the value chain dynamics of improved cook stove initiatives. Sustain. Energy Technol. Assess. 2017, 22, 171-176. [CrossRef]

41. Ministry of Environment and Natural Resources. Kenya's Intended Nationally Determined Contribution (INDC); Ministry of Environment and Natural Resources: Nairobi, Kenya, 2015.

42. Wernet, G.; Bauer, C.; Steubing, B.; Reinhard, J.; Moreno-Ruiz, E.; Weidema, B. The ecoinvent database version 3 (part I): Overview and methodology. Int. J. Life Cycle Assess. 2016, 21, 1218-1230. [CrossRef]

43. Kadian, R.; Dahiya, R.P.; Garg, H.P. Energy-related emissions and mitigation opportunities from the household sector in Delhi. Energy Policy 2007, 35, 6195-6211. [CrossRef]

44. Emodi, N.V.; Emodi, C.C.; Murthy, G.P.; Emodi, A.S.A. Energy policy for low carbon development in Nigeria: A LEAP model application. Renew. Sustain. Energy Rev. 2017, 68, 247-261. [CrossRef]

45. Limmeechokchai, B.; Chawana, S. Sustainable energy development strategies in the rural Thailand: The case of the improved cooking stove and the small biogas digester. Renew. Sustain. Energy Rev. 2007, 11, 818-837. [CrossRef]

46. KNBS. Kenya Census Population Statistics 2019; KNBS: Nairobi, Kenya, 2019.

47. IMF. World Economic Outlook (WEO) Database; IMF: Washington, DC, USA, April 2018; p. 2015.

48. Trading Economics. Kenya GDP Per Capita 1960-2018. Available online: https://tradingeconomics.com/ kenya/gdp-per-capita (accessed on 17 July 2018).

49. Government of Kenya. Kisumu County Fact Sheet-1. 2015; Government of Kenya: Nairobi, Kenya, 2015; pp. 1-15.

50. UN-Habitat. Kisumu City Development Strategies (2004-2009); United Nations: Nairobi, Kenya, 2004.

51. Smith, K.R.; Uma, R.; Kishore, V.V.N.; Lata, K.; Joshi, V.; Zhang, J.; Rasmussen, R.A.; Khalil, M.A.K. Greenhouse Gases from Small-Scale Combustion Devices in Developing Countries, Phase II a, Household Stoves in India; United States Environmental Protection Agency: Washington, DC, USA, 2000.

52. Jetter, J.; Zhao, Y.; Smith, K.R.; Khan, B.; Yelverton, T.; Decarlo, P.; Hays, M.D. Pollutant emissions and energy efficiency under controlled conditions for household biomass cookstoves and implications for metrics useful in setting international test standards. Environ. Sci. Technol. 2012, 46, 10827-10834. [CrossRef] 
53. MacCarty, N.; Still, D.; Ogle, D. Fuel use and emissions performance of fifty cooking stoves in the laboratory and related benchmarks of performance. Energy Sustain. Dev. 2010, 14, 161-171. [CrossRef]

54. Magambo, B.; Kiremu, C. A Study of Household Eletricity Demand and Consumption Patterns in Nairobi. Master Thesis, University of Nairobi, Nairobi, Kenya, 2010.

55. KNBS. County Statistical Abstract Kisumu County 2015; Kenya National Bureau of Statistics: Nairobi, Kenya, 2015; pp. 1-19.

56. Huijbregts, M.A.J.; Steinmann, Z.J.N.; Elshout, P.M.F.; Stam, G. ReCiPe 2016: A Harmonized Life Cycle Impact Assessment Method at Midpoint and Endpoint Level Report I: Characterization; National Institute for Public Health and the Environment: Bilthoven, The Netherlands, 2016.

57. Morelli, B.; Cashman, S.; Rodgers, M. Life Cycle Assessment of Cookstoves and Fuels in India, China, Kenya and Ghana; United States Environmental Protection Agency: Washington, DC, USA, 2017.

58. Milà i Canals, A.; Azapagic, A.; Doka, G.; Jefferies, D.; King, H.; Mutel, C.; Nemecek, T.; Roches, A.; Sim, S.; Stichnothe, H.; et al. Approaches for Addressing Life Cycle Assessment Data Gaps for Bio-based Products. J. Ind. Ecol. 2011, 15, 707-725. [CrossRef]

(C) 2020 by the authors. Licensee MDPI, Basel, Switzerland. This article is an open access article distributed under the terms and conditions of the Creative Commons Attribution (CC BY) license (http://creativecommons.org/licenses/by/4.0/). 